\title{
White Matter Abnormalities Track Disease Progression in PSEN1 Autosomal Dominant Alzheimer's Disease
}

\author{
Raquel Sánchez-Valle ${ }^{\mathrm{a}, \mathrm{b}, *}$, Gemma C. Monté ${ }^{\mathrm{b}}$, Roser Sala-Llonch ${ }^{\mathrm{c}}$, Beatriz Bosch ${ }^{\mathrm{a}, \mathrm{b}}$, Juan Fortea ${ }^{\mathrm{d}}$, \\ Albert Lladó $^{\mathrm{a}, \mathrm{b}}$, Anna Antonell ${ }^{\mathrm{a}, \mathrm{b}}$, Mircea Balasa ${ }^{\mathrm{a}, \mathrm{b}}$, Nuria Bargallób ${ }^{\mathrm{b}, \mathrm{e}}$ and José Luis Molinuevo ${ }^{\mathrm{a}, \mathrm{b}}$ \\ aAlzheimer's Disease and Other Cognitive Disorders Unit, Department of Neurology, Hospital Clínic, \\ Barcelona, Spain \\ ${ }^{\mathrm{b}}$ Institut d'Investigació Biomèdica August Pi i Sunyer (IDIBAPS), Barcelona, Spain \\ ${ }^{\mathrm{c}}$ Research Group for Lifespan Changes in Brain and Cognition (LCBC), Department of Psychology, \\ University of Oslo, Norway \\ ${ }^{\mathrm{d}}$ Memory Unit, Department of Neurology, Hospital de Sant Pau, Barcelona, Spain \\ ${ }^{\mathrm{e}}$ Department of Radiology, Hospital Clínic, Barcelona, Spain
}

Accepted 27 December 2015

\begin{abstract}
PSEN1 mutations are the most frequent cause of autosomal dominant Alzheimer's disease (ADAD), and show nearly full penetrance. There is presently increasing interest in the study of biomarkers that track disease progression in order to test therapeutic interventions in ADAD. We used white mater (WM) volumetric characteristics and diffusion tensor imaging (DTI) metrics to investigate correlations with the normalized time to expected symptoms onset (relative age ratio) and group differences in a cohort of 36 subjects from PSEN1 ADAD families: 22 mutation carriers, 10 symptomatic (SMC) and 12 asymptomatic (AMC), and 14 non-carriers (NC). Subjects underwent a 3T MRI. WM morphometric data and DTI metrics were analyzed. We found that PSEN1 MC showed significant negative correlation between fractional anisotropy (FA) and the relative age ratio in the genus and body of corpus callosum and corona radiate $(p<0.05$ Family-wise error correction (FWE) at cluster level) and positive correlation with mean diffusivity (MD), axial diffusivity (AxD), and radial diffusivity (RD) in the splenium of corpus callosum. SMC presented WM volume loss, reduced FA and increased MD, AxD, and RD in the anterior and posterior corona radiate, corpus callosum $(p<0.05 \mathrm{FWE})$ compared with NC. No significant differences were observed between AMC and NC in WM volume or DTI measures. These findings suggest that the integrity of the WM deteriorates linearly in PSEN1 ADAD from the early phases of the disease; thus DTI metrics might be useful to monitor the disease progression. However, the lack of significant alterations at the preclinical stages suggests that these indexes might not be good candidates for early markers of the disease.
\end{abstract}

Keywords: Alzheimer's disease, diffusion tensor imaging, magnetic resonance imaging, presenilin 1, white matter

\footnotetext{
*Correspondence to: Raquel Sánchez-Valle, Alzheimer's Disease and Other Cognitive Disorders Unit, Department of Neurology, Hospital Clínic, Villarroel, 170, 08036 Barcelona, Spain. Tel.: +34 932275785; Fax: +34 932275783; E-mail: rsanchez@ clinic.ub.es.
}

\section{INTRODUCTION}

A small minority of Alzheimer's disease (AD) cases are inherited with an autosomal dominant pattern of inheritance, caused by a mutation in the presenilin-1 (PSEN1), amyloid precursor protein, or presenilin-2 genes. These forms, also called autosomal dominant AD (ADAD), show almost $100 \%$ penetrance and 
present an early age of onset, which is relatively predictable in a given family [1] and thus, represent a population in whom treatment could be initiated at early phases of the disease, even at a presymptomatic stage [2]. In this sense, two trials: the Dominantly Inherited Alzheimer Network Trials Unit (DIANTU) (ClinicalTrials.gov Identifier: NCT01760005) $[2,3]$ and the Alzheimer's Prevention Initiative (API) Colombian trial (NCT01998841) [2, 4] are already ongoing and aim to evaluate the safety and efficacy of different drugs in ADAD. Although regulatory agencies require the presence of significant benefit in cognition even in prevention treatment trials, there is considerable effort in searching for non-invasive biomarkers that could act as surrogate markers or provide evidence of disease modification [5, 6].

$\mathrm{AD}$ is traditionally considered mainly a disease of the grey matter (GM). In this sense, to date, morphometric GM or whole brain measures are the main neuroimaging biomarkers included in clinical trials, based on the extensive literature in mild cognitive impairment and dementia due to AD patients, both in sporadic [7] and ADAD [8-10]. However, there is some evidence that suggest that GM morphometric measures may suffer unexpected effects with anti-amyloid therapies [11] or present non-linear trajectories in different brain areas [12-15] that may lead to difficulty in their interpretation in clinical trials. On the other hand, thanks to the advances in MRI-related techniques, white-matter (WM) tract disruption is becoming a well described early event in $\mathrm{AD}$, and although it is thought to be mainly secondary to GM damage, other hypotheses, that WM and GM loss are different effects of a common upstream pathological process, have been also proposed [16, 17].

Diffusion tensor imaging (DTI) measures the diffusion directionality of water molecules in brain tissue, and the study of the different DTI metrics could be of interest for capturing additional or complementary markers of neurodegeneration [18]. In this sense, fractional anisotropy (FA) reflects how directionally constrained the diffusion of water is along axons and lower FA supports loss of WM integrity. Axial diffusivity (AxD) measures diffusion parallel to axonal fibers, radial diffusivity (RD) perpendicular diffusion, and mean diffusivity (MD) the average rate of diffusion in all directions, and generally increases with WM injury [19].

Prior DTI studies in sporadic AD have reported lower FA and increased $\mathrm{MD}, \mathrm{RD}$, and/or $\mathrm{AxD}$, throughout WM, mainly in the corpus callosum, fornix, cingulum, superior longitudinal fasciculus, and inferior longitudinal fasciculus [19-22]. Some of these studies also demonstrated strong correlation with widely-used clinical measures [20, 23, 24].

There are scarce and conflicting data about WM abnormalities and WM DTI metrics in ADAD, but based on the available results in both sporadic and ADAD, we hypothesized that WM in ADAD would deteriorate with disease progression. Thus, here, we investigate WM structural and DTI metrics in ADAD due to PSEN1 mutations and their correlation with the time to expected symptoms onset in order to provide exploratory evidence of the potential use of these markers in ADAD trials.

\section{MATERIALS AND METHODS}

\section{Subjects}

Thirty-six adult participants from ADAD families with 9 different PSEN1 mutations (M139T, S169P, G209E，R220G，L235R，K239N，L282R，L286P, I439S) were recruited from the genetic counseling program for familial dementias (PICOGEN) at the Hospital Clinic, Barcelona, Spain [12]. Subjects were made aware of their at-risk status for genetic AD in a session of genetic counseling and were given the option of knowing their genetic status through the genetic counseling protocol. The study was approved by the Hospital Clinic ethics committee, and all subjects gave written informed consent.

\section{Genetic analysis}

Genomic DNA was extracted from peripheral blood using the QIAamp DNA Blood Mini Kit (Qiagen). Mutation screening was performed by direct sequencing.

\section{Clinical and neuropsychological characterization}

Subjects underwent clinical and cognitive assessments, and a comprehensive neuropsychological battery was also administered, as described previously [13].

Subjects were classified as asymptomatic if they had no memory complaints, they scored 0 on the Clinical Dementia Rating (CDR) scale, and their cognitive performance was within the mean \pm 1.5 SD with respect to control scores from their age and educational level on all the cognitive tests. 
Participants were classified as symptomatic if their CDR score was $>0$ or if their cognitive performance was more than 1.5 SD below the mean with respect to their age and educational level on any cognitive test.

To evaluate the time to expected symptoms onset of each mutation carrier (MC), we calculated the relative or adjusted age as the subject's age relative to the median age of onset in their family (absolute age - median age of onset in their family), similar to previous studies in ADAD [1, 8-10, 12]. The range of the median age of onset in the families included in this study is wide (range 31-61 years). As the same distance to symptoms onset expressed in years might have different biological effects in subjects with different expected ages of onset (that is, a period of 10 years is almost one third of the biological life until symptoms onset in subjects with an expected age of onset of 31 but only one sixth in subjects with expected symptoms onset at 61), we defined and calculated for each mutation carrier the relative age ratio defined as the relative age divided by the median age of onset in the family (relative age ratio $=[$ absolute age - median age of onset in their family $] /$ median age of onset in their family) in order to compare subjects from different families with different median ages of onset.

\section{MRI scanning}

All subjects were scanned in the same 3T scan (Siemens Trio Tim, Siemens, Germany). The study included a high-resolution 3D structural dataset (T1-weighted MP-RAGE, voxel size $=1.0 \times$ $1.0 \times 1.0 \mathrm{~mm}, \quad \mathrm{TR}=2300 \mathrm{~ms}, \quad \mathrm{TE}=2.98 \mathrm{~ms}, \quad 240$ slices, $\mathrm{FOV}=256 \mathrm{~mm}$, matrix size $=256 \times 256$, slice thickness $=1 \mathrm{~mm}$ ). The DTI protocol consisted of an echo-planar imaging (EPI) sequence with coverage of the whole head ( 30 directions $+\mathrm{b} 0$ image, with two repeated acquisitions, $\mathrm{TR}=7600 \mathrm{~ms}, \mathrm{TE}=89 \mathrm{~ms}, 60$ slices, slice thickness $=2 \mathrm{~mm}$, distance factor $=0 \%$, FOV $=250 \mathrm{~mm}$, matrix size $=122 \times 122$, voxel size $=2 \times 2 \times 2 \mathrm{~mm}$ ). Two identical DTI runs were acquired.

\section{Preprocessing of volumetric data}

The T1-weigthed images were visually inspected for possible artifacts and Fluid-attenuated inversion recovery (FLAIR) T2-weighted images for white matter hyperintensities. Next, a VBM-type pre-processing was conducted. Default segmentation implemented in SPM12 (Wellcome Trust Centre for Neuroimaging, UK) was used for extracting WM tissue class. Normalization to the same stereotaxic space was performed by Dartel [25]. Finally, warped WM images were modulated and smoothed with $8 \mathrm{~mm}$ of FWHM.

\section{Preprocessing of DTI data}

Data were visually inspected for possible artifacts and damaged volumes. Next, the two runs acquired were concatenated in a single file and reoriented jointly to the structural MRI data. FA, MD, AxD, and RD maps were obtained using FDT (FMRIB's Diffusion Toolbox) implemented in FSL (FMRIB Software Library, Oxford, UK). Prior to the DTI calculation, diffusion images were corrected for eddy current distortion, corrected for motion, and registered to b0 image using FLIRT [26].

For intra-subject registration, SPM12 was used. Diffusion metrics (FA, MD, RD, and AxD) were first linearly co-registered to their corresponding T1 images. Next, inter-subject registration was performed using Dartel [25]. It was done using same flow fields from the VBM-type preprocessing above described, these flow fields were applied to the diffusion data that were finally normalized to the MNI space. At the end, the non-linearly registered diffusion data were smoothed applying an isotropic Gaussian kernel with $8 \mathrm{~mm}$ of FWHM.

\section{Statistical analysis}

The same statistical procedures were applied to structural and diffusion data using SPM12 package. Firstly, we performed linear regression with the relative age ratio in PSEN1 MC. To avoid redundancies with the relative age ratio in the matrix design, only gender was used as covariate. For the VBM analysis, total intracranial volume (TIV) was additionally entered as global.

Secondly, we performed a $t$-test comparison between groups: NC versus AMC, NC versus SMC, and AMC versus SMC. The design included age and gender as covariates. TIV was used as a covariate only in the VBM analysis.

Statistical analyses were performed using a WM mask in the MNI space, obtained from the own customized warped WM. The mask was fitted using absolute threshold 0.25 . The fornix region extracted from the JHU-DTI with matter atlas (John Hopkins University, Laboratory of brain anatomical MRI; 
Table 1

Demographic data and Mini-Mental State Examination (MMSE) score. Values are mean $(\mathrm{SD}) ;{ }^{*} p<0.01$ compared with $\mathrm{NC}$ and AMC

\begin{tabular}{lccc}
\hline & $\mathrm{NC}(n=14)$ & $\mathrm{AMC}(n=12)$ & $\mathrm{SMC}(n=10)$ \\
\hline $\begin{array}{l}\text { Absolute age } \\
\text { in years (SD) }\end{array}$ & $39.04(9.5)$ & $39.18(10.37)$ & $46.63(9.13)^{*}$ \\
$\begin{array}{l}\text { Relative age } \\
\text { in years (SD) }\end{array}$ & $-8.89(8.70)$ & $-12.90(8.72)$ & $2.83(3.27)^{*}$ \\
$\begin{array}{l}\text { Relative age } \\
\text { ratio (SD) }\end{array}$ & $-0.18(0.16)$ & $-0.25(0.17)$ & $0.061(0.07)^{*}$ \\
$\begin{array}{l}\text { Gender, M/W } \\
\text { Formal education }\end{array}$ & $12.07(2.20)$ & $13.25(2.49)$ & $9.6(4.14)$ \\
in years (SD) & & & \\
MMSE & 29.43 & 29.25 & $21.00^{*}$ \\
(SD, range $)$ & $(0.64,28-30)$ & $(1.05,27-30)$ & $(5.27,12-28)$ \\
& 29.43 & 29.25 & 21.00 \\
\hline
\end{tabular}

cmrm.med.jhmi.edu) was added to this mask to ensure this area was also included in the statistics.

Statistical analyses were performed by fitting a voxel-wise general linear model (GLM), resulting maps were corrected for multiple comparisons using Family-wise Error (FEW) correction. We used a significance threshold of corrected FWE $p<0.05$ from a map uncorrected $p<0.001$ (the map became then corrected at cluster level). Only clusters wider than 50 voxels were considered. Brain locations of the results were reported by means of the JHU-DTI white-matter atlas.

For demographics and clinical data, group analyses were conducted using PASW (Predictive Analytics SoftWare, IBM Corp.) v.18. Comparisons between groups were performed using the two-tailed Student's $t$ test or ANOVA for continuous variables, and a chi square test for categorical variables.

\section{RESULTS}

\section{Demographics and clinical classification}

Demographic and clinical data of the participants are summarized in Table 1.

Twenty-two subjects were mutation carriers with a mean absolute age of 42.57 years (SD 10.32). Twelve of the mutation carriers were AMC and 10 SMC (Table 1), 7 of the SMC met criteria for dementia at inclusion. Fourteen subjects were NC, with a mean absolute age of 39.18 years (SD 10.37). All the NC were cognitively normal and scored 0 on CDR. Absolute age did not differ between $\mathrm{NC}$ and the whole sample of mutation carriers or AMC, but as expected, SMC were older than both NC and AMC, and presented significantly lower MMSE scores $(p<0.01)$.
No relevant WM hyperintensities (Fazekas scale <1) have been observed in participants at visual inspection in FLAIR weighted images.

\section{White matter metrics and the relative age ratio in PSEN1 mutation carriers}

FA values inversely correlated with the relative age ratio in PSEN1 mutation carriers (Fig. 1). Significant correlations were found in right anterior corona radiata $(\mathrm{Z} \max =4.31, k=1905$ voxels, MNI coordinate $[18,32,16])$ involving the genu and body of corpus callosum (Fig. 1a). The forceps minor, cingulate gyrus, inferior fronto-occipital, and uncinate fasciculus were also affected. Another significant cluster was found in the left anterior corona radiate and anterior thalamic radiation $(\mathrm{Z} \max =4.28, k=678$ voxels, MNI coordinate $[-15,27,22])$, also including the genu and body of corpus callosum.

MD values directly correlated with the relative age ratio in PSEN1 mutation carriers (Fig. 1b). Clusters distribution appeared bilateral and symmetric. The first cluster $(\mathrm{Z} \max =4.03, k=2687$ voxels, MNI coordinate $[16,-38,8]$ ) was localized in the right splenium and body of corpus callosum, and the fronto-occipital fasciculus. This cluster extended toward the right posterior thalamic radiation and retrolenticular part of the internal capsule and the fornix (cres)/stria terminalis. The second cluster $(\mathrm{Zmax}=3.91, k=1656$ voxels, MNI coordinate $[-15$, $-46,0]$ ) was centered in the left cingulum (hippocampus) and forceps major tract and the fornix (cres) stria terminalis; it also reached the posterior thalamic radiation and the retrolenticular part of the internal capsule.

AxD and RD values showed similar results to MD values and presented positive correlation with the relative age ratio in areas of the splenium and body of corpus callosum, posterior thalamic radiation and retrolenticular part of the internal capsule and the fornix (cres)/stria terminalis.

We did not find any significant correlation between DTI measures and subjects' age in NC.

The volumetric analysis showed an inverse correlation between $\mathrm{WM}$ volume and the relative age ratio in PSEN1 mutation carriers in the fornix (column and body) ( $p<0.001$ unc., $Z \max =4.11, k=68$ voxels, MNI coordinate $[-2,-21,18])$, and the body of corpus callosum $(p<0.001$ unc., $\mathrm{Z} \max =3.78, k=107$ voxels, MNI coordinate $[-2,-24,20])$. However, these clusters did not survive the threshold at a cluster level. 

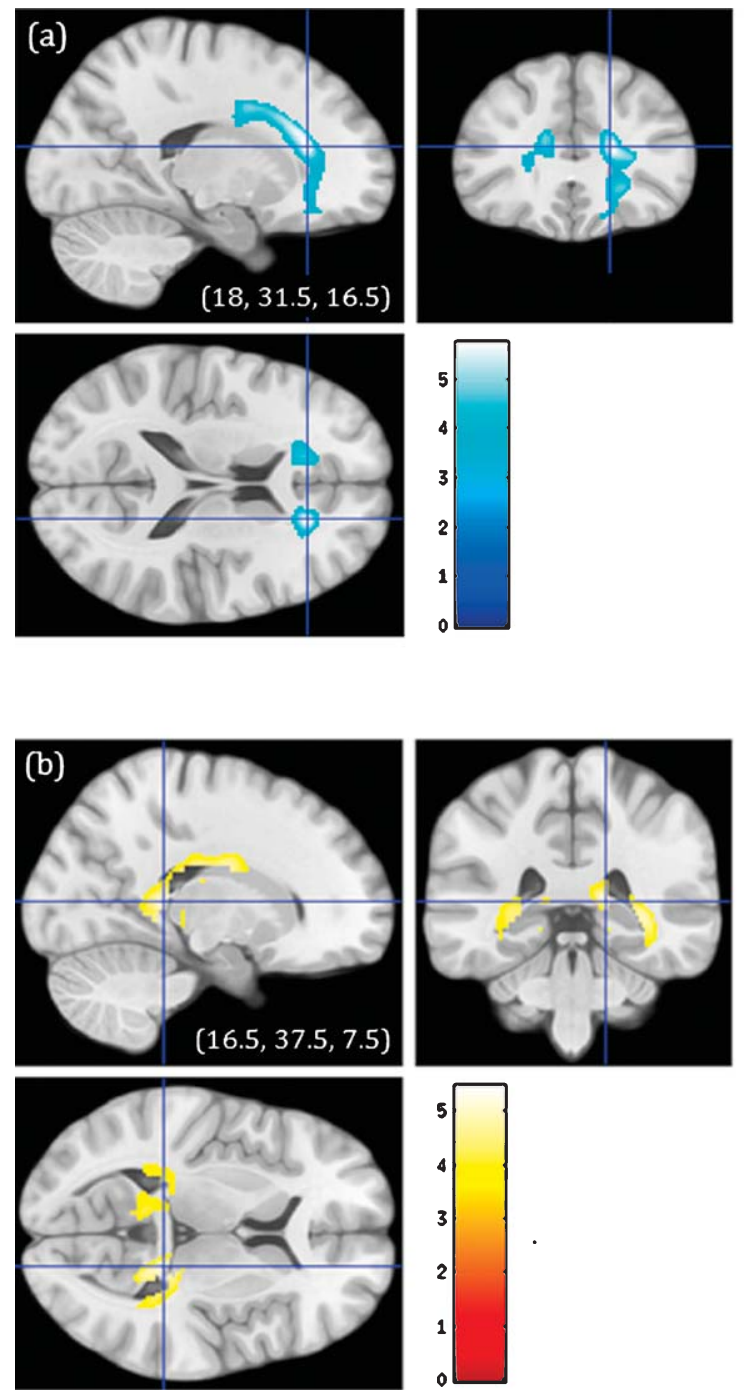
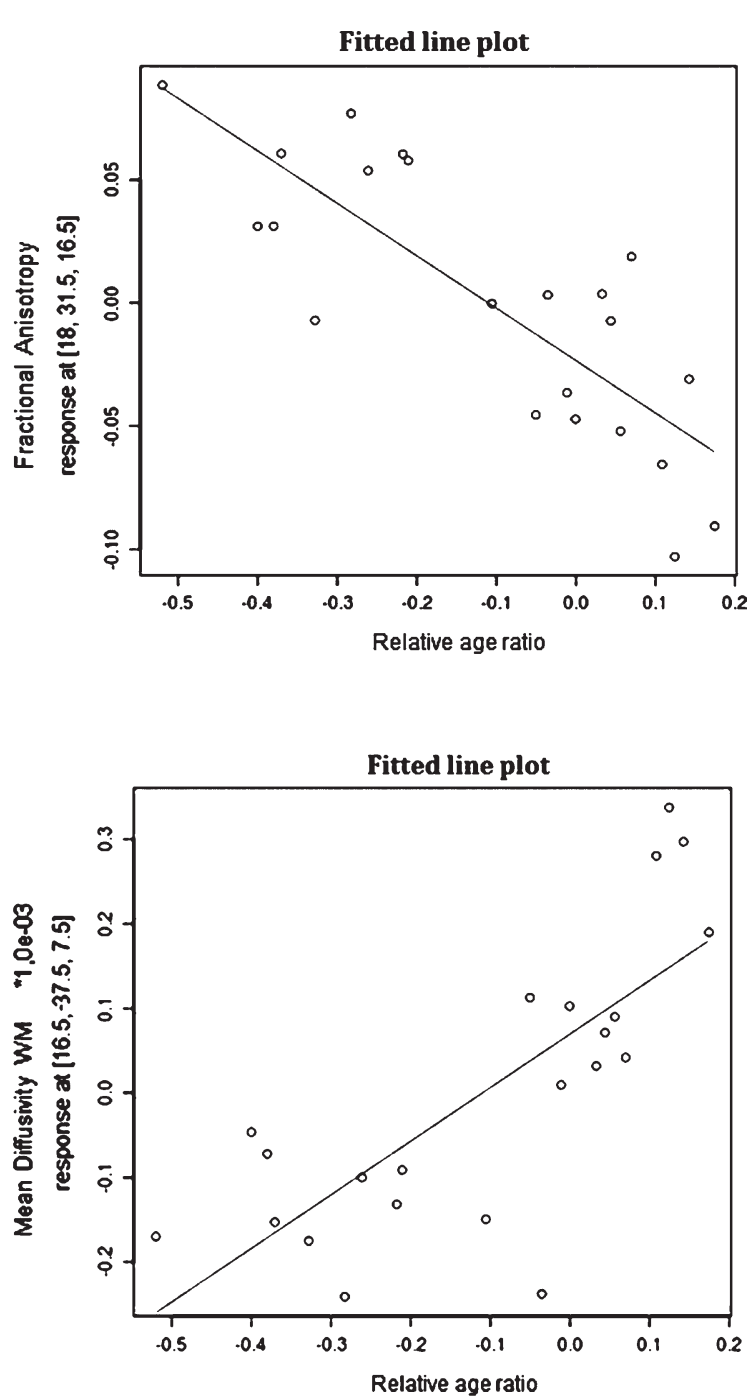

Fig. 1. DTI metrics correlation with the relative age ratio in PSEN1 mutation carriers ( $p<0.05$ FWE corrected at cluster-level): (a) Areas of significant inverse correlation with Fractional anysotropy (FA) values and fitted line plot of FA values in right corona radiata ( $\mathrm{Z}$ max: 18 , 32, 16); Adjusted R-squared $=0.61^{*}$. (b) Areas of positive significant correlation with mean diffusivity (MD) values and fitted line plot of $\mathrm{MD}$ values in splenium of corpus callosum ( $\mathrm{Z}$ max: $16-38,8)$. Adjusted $\mathrm{R}$-squared $=0.56^{*}$ (*models were adjusted by absolute age).

\section{White matter volumetric data: group analysis}

PSEN1 SMC showed reduced WM volume compared with $\mathrm{NC}$ in the anterior and posterior corona radiata and posterior thalamic track the left superior and inferior longitudinal fasciculus, inferior fronto-occipital, and uncinated fasciculus $(Z=4.07$, $k=3737,[-44,-38,0])(p<0.05$ FWE at cluster level (Fig. 2)). A second significant cluster was observed in the genus of corpus callosum, cingulate gyrus, and the forceps minor $(Z=8.34, k=1476$, $[-8,30,15])$; it included the inferior fronto-temporal fasciculus, anterior thalamic radiation, superior longitudinal fasciculus, and forceps minor tracts.
No significant differences were observed between $\mathrm{AMC}$ and NC.

\section{Diffusion tensor imaging metrics: group analysis}

SMC showed significant reduced FA compared with NC in the body of corpus callosum and bilateral anterior corona radiata $(Z=5.22, k=2235),[28$, $34,12])$ and posterior thalamic radiation (Fig. 3). SMC presented increased MD, RD and AxD in extensive areas of WM $(Z=5.65, k=75726),[20$, $-32,3])$ : genum, body and splenium of corpus callosum, cingulate gyrus, superior and inferior 


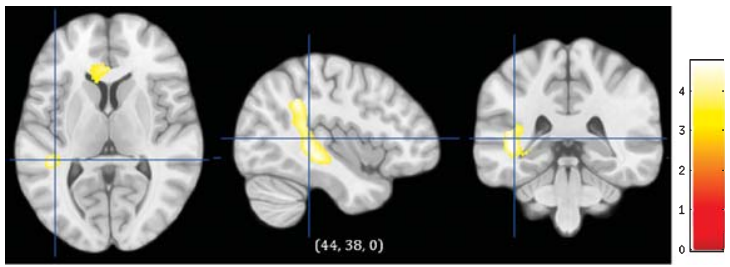

Fig. 2. Areas of WM volume loss in SMC compared with NC $(p<0.05 \mathrm{FWE}$ at cluster level; age and gender as covariates).
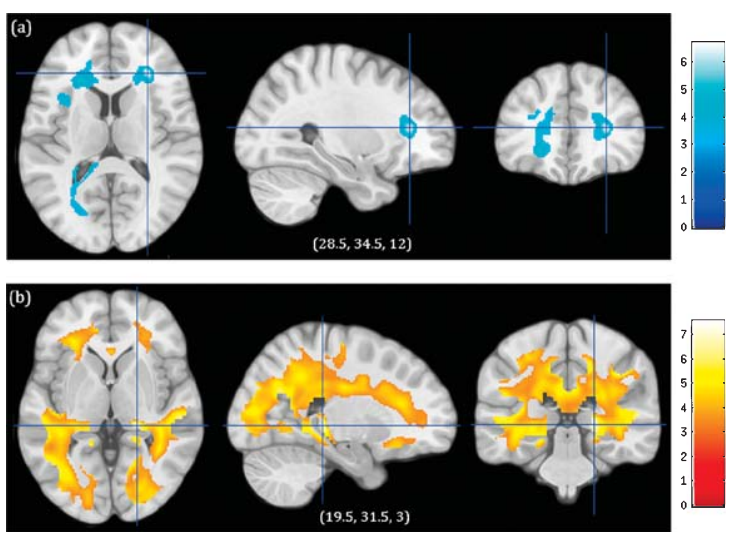

Fig. 3. DTI metrics in symptomatic mutation carriers (SMC) compared with non-carriers (NC). (a) Fractional anisotropy: SMC $<$ NC. (b) Mean diffusivity: SMC $>$ NC $(p<0.05$ FWE corrected at cluster level; age and gender as covariates).

longitudinal fasciculi, fronto-occipital fasciculi, anterior and posterior corona radiata, and posterior thalamic radiation.

No significant differences were observed in AMC compared with NC.

\section{DISCUSSION}

We performed a morphometric analysis of WM PSENI ADAD to assess the integrity of WM in these subjects and to study the relationship between WM integrity and time to expected symptoms onset. With DTI, we found that FA, MD, AxD, and RD values correlated with distance to symptoms onset in the whole sample of MC. However, group differences, both in DTI metrics and volumetric analyses, were only significant in the SMC group.

To the best of our knowledge, this is the first study to examine the relationship of DTI metrics and the relative distance of symptoms onset in ADAD. FA values decrease linearly in the genus and anterior body of the corpus callosum and anterior corona radiate from values of subjects far from symptoms onset to those of subjects older than expected age of onset and already symptomatic. The maps of areas with significant correlation of FA with the relative distance of symptoms onset and those of areas with significant FA reduction in SMC are quite similar, suggesting that the disconnection process is a progressive part of the pathophysiological mechanism underlying brain alterations in ADAD. As expected, MD, AxD, and $R D$ values evolve in the opposite sense, with increasing values as the subjects became closer to symptoms onset or already symptomatic, in the body and splenium of corpus callosum.

As regards as WM volumetric analysis, there are also scarce studies available focused in the study of the WM integrity in ADAD. Cash et al. performed a VBM study in the Dominantly Inherited Alzheimer Network (DIAN) cohort and found that WM was reduced in cingulum, fornix, and areas close to the posterior cingulate and precuneus in $50 \mathrm{SMC}$ compared with NC. The authors stated that caution should be taken when interpreting these data, due to technical difficulties in the WM parcellation using VBM. As most of the WM changes overlap areas that predominantly contain GM, the results may reflect GM atrophy rather than actual WM difference [27]. In our morphometric study, SMC also showed volume loss in relevant WM areas. We did not find significant differences between AMC and NC. However, as Cash et al. suggested, we also think that VBM analysis might not be the optimal technique to study WM alterations in ADAD.

With respect to previous studies on DTI metrics in ADAD, Ringman et al. [28] found that ADAD mutation carriers $(n=12)$, presented decreased mean whole brain white-matter FA and FA values in the columns of the fornix, areas of the perforant pathways bilaterally and left orbitofrontal lobe relative to that of $\mathrm{NC}(n=8)$ in a region of interest (ROI) analysis. They also found that FA in the columns of the fornix and left orbitofrontal lobe were significantly decreased in the eight presymptomatic mutation carriers. In our study, neither the fornix nor the orbitofrontal lobe arose as significant areas of different FA values in any of the group comparisons performed, although we performed a whole-brain analysis instead ROI type of analysis. In this sense, our results were more similar to those of Parra et al. [29] performed in the Colombian E180A PSEN1 cohort, even if they also used the ROI approach, and AMC versus $\mathrm{NC}$ analysis revealed no significant differences in any of the DTI metrics. In contrast, and similar to our findings, group comparisons between SMC and NC showed that patients 
had higher MD in the body and splenium of corpus callosum, cingulum, and frontal WM.

Another study performed in a cohort of 10 PSEN1 and APP symptomatic and asymptomatic MC also showed significantly increased MD in the inferior and superior longitudinal fasciculus and cingulum in MC compared with controls [30]. However, in the same study, MD was still significantly increased in these areas when the presymptomatic MC were analyzed alone. Subtle differences in the methods of analysis, relative age of the AMC, or type of mutations included could account for these differences with our results. In this sense, a recent series [31] and several previous case reports [32-34] have underlined relevant differences in the WM abnormalities, both in neuroimaging and neuropathological studies, within ADAD cases, related to the site of the causal mutation in the PSEN1 or APP genes.

We think that the main limitation of our study is the relatively small sample size that may limit the interpretation of the results, especially in the AMC group analysis, and prevent some potential analysis of interest. However, previous investigations of WM measures in ADAD neuroimaging have similar sample sizes and our main results survived a correction for multiple comparisons.

In summary, we think that our findings support the idea that the WM deteriorates progressively in PSEN1 ADAD with disease evolution. In this sense, DTI metrics, even if they may not be useful to detect early preclinical phases of the ADAD neuropathological process, might monitor the disease progression. Longitudinal and multicentric studies will be needed to confirm these exploratory results.

\section{ACKNOWLEDGMENTS}

This work has been supported by research grants to RSV (FIS080036 and FIS1200013, Plan Nacional de I + D + I, co-funded by Instituto de Salud Carlos III and the European Region Development fund, FEDER) and the Innovative Medicines Initiative Joint Undertaking under grant agreement $\mathrm{n}^{\circ} 115568$, resources of which are composed of financial contribution from the European Union's Seventh Framework Programme (FP7/2007-2013) and EFPIA companies' in kind contribution.

We thank all the volunteers for their participation in this study.

Authors' disclosures available online (http://j-alz. com/manuscript-disclosures/15-0899r2).

\section{REFERENCES}

[1] Ryman DC, Acosta-Baena N, Aisen PS, Bird T, Danek A, Fox NC, Goate A, Frommelt P, Ghetti B, Langbaum JB, Lopera F, Martins R, Masters CL, Mayeux RP, McDade E, Moreno S, Reiman EM, Ringman JM, Salloway S, Schofield PR, Sperling R, Tariot PN, Xiong C, Morris JC, Bateman RJ, Dominantly Inherited Alzheimer Network (2014) Symptom onset in autosomal dominant Alzheimer disease: A systematic review and meta-analysis. Neurology 83, 253-260.

[2] Carrillo MC, Brashear HR, Logovinsky V, Ryan JM, Feldman HH, Siemers ER, Abushakra S, Hartley DM, Petersen RC, Khachaturian AS, Sperling RA (2013) Can we prevent Alzheimer's disease? Secondary "prevention" trials in Alzheimer's disease. Alzheimers Dement 9, 123-131.

[3] Mills SM, Mallmann J, Santacruz AM, Fuqua A, Carril M, Aisen PS, Althage MC, Belyew S, Benzinger TL, Brooks WS, Buckles VD, Cairns NJ, Clifford D, Danek A, Fagan AM, Farlow M, Fox N, Ghetti B, Goate AM, Heinrichs D, Hornbeck R, Jack C, Jucker M, Klunk WE, Marcus DS, Martins RN, Masters CM, Mayeux R, McDade E, Morris JC, Oliver A, Ringman JM, Rossor MN, Salloway S, Schofield PR, Snider J, Snyder P, Sperling RA, Stewart C, Thomas RG, Xiong C, Bateman RJ (2013) Preclinical trials in autosomal dominant AD: Implementation of the DIAN-TU trial. Rev Neurol (Paris) 169, 737-743.

[4] Reiman EM, Langbaum JB, Fleisher AS, Caselli RJ, Chen K, Ayutyanont N, Quiroz YT, Kosik KS, Lopera F, Tariot PN (2011) Alzheimer's Prevention Initiative: A plan to accelerate the evaluation of presymptomatic treatments. $J$ Alzheimers Dis 26, 321-329.

[5] Morris JC, Selkoe DJ (2011) Recommendations for the incorporation of biomarkers into Alzheimer clinical trials: An overview. Neurobiol Aging 32, S1-S3.

[6] Moulder KL, Snider BJ, Mills SL, Buckles VD, Santacruz AM, Bateman RJ, Morris JC (2013) Dominantly Inherited Alzheimer Network: Facilitating research and clinical trials. Alzheimers Res Ther 17, 48.

[7] Weiner MW, Veitch DP, Aisen PS, Beckett LA, Cairns NJ, Green RC, Harvey D, Jack CR, Jagust W, Liu E, Morris JC, Petersen RC, Saykin AJ, Schmidt ME, Shaw L, Shen L, Siuciak JA, Soares H, Toga AW, Trojanowski JQ, Alzheimer's Disease Neuroimaging Initiative (2013) The Alzheimer's Disease Neuroimaging Initiative: A review of papers published since its inception. Alzheimers Dement 9, e111-e194.

[8] Bateman RJ, Xiong C, Benzinger TL, Fagan AM, Goate A, Fox NC, Marcus DS, Cairns NJ, Xie X, Blazey TM, Holtzman DM, Santacruz A, Buckles V, Oliver A, Moulder K, Aisen PS, Ghetti B, Klunk WE, McDade E, Martins RN, Masters CL, Mayeux R, Ringman JM, Rossor MN, Schofield PR, Sperling RA, Salloway S, Morris JC, Dominantly Inherited Alzheimer Network (2012) Clinical and biomarker changes in dominantly inherited Alzheimer's disease. N Engl J Med 367, 795-804.

[9] Reiman EM, Quiroz YT, Fleisher AS, Chen K, Velez-Pardo C, Jimenez-Del-Rio M, Fagan AM, Shah AR, Alvarez S, Arbelaez A, Giraldo M, Acosta-Baena N, Sperling RA, Dickerson B, Stern CE, Tirado V, Munoz C, Reiman RA, Huentelman MJ, Alexander GE, Langbaum JB, Kosik KS, Tariot PN, Lopera F (2012) Brain imaging and fluid biomarker analysis in young adults at genetic risk for autosomal dominant Alzheimer's disease in the presenilin 1 E280A kindred: A case-control study. Lancet Neurol 11, 1048-1056. 
[10] Ridha BH, Barnes J, Bartlett JW, Godbolt A, Pepple T, Rossor MN, Fox NC (2006) Tracking atrophy progression in familial Alzheimer's disease: A serial MRI study. Lancet Neurol 5, 828-834.

[11] Fox NC, Black RS, Gilman S, Rossor MN, Griffith SG, Jenkins L, Koller M, AN1792(QS-21)-201, Study (2005) Effects of Abeta immunization (AN1792) on MRI measures of cerebral volume in Alzheimer disease. Neurology 64, 1563-1572.

[12] Fortea J, Sala-Llonch R, Bartres-Faz D, Bosch B, Llado A, Bargallo N, Molinuevo JL, Sanchez-Valle R (2010) Increased cortical thickness and caudate volume precede atrophy in PSEN1 mutation carriers. J Alzheimers Dis 22, 909-922.

[13] Sala-Llonch R, Lladó A, Fortea J, Bosch B, Antonell A, Balasa M, Bargalló N, Bartrés-Faz D, Molinuevo JL, SánchezValle R (2015) Evolving brain structural changes in PSEN1 mutation carriers. Neurobiol Aging 36, 1261-1270.

[14] Benzinger TL, Blazey T, Jack CR Jr, Koeppe RA, Su Y, Xiong C, Raichle ME, Snyder AZ, Ances BM, Bateman RJ, Cairns NJ, Fagan AM, Goate A, Marcus DS, Aisen PS, Christensen JJ, Ercole L, Hornbeck RC, Farrar AM, Aldea P, Jasielec MS, Owen CJ, Xie X, Mayeux R, Brickman A, McDade E, Klunk W, Mathis CA, Ringman J, Thompson PM, Ghetti B, Saykin AJ, Sperling RA, Johnson KA, Salloway S, Correia S, Schofield PR, Masters CL, Rowe C, Villemagne VL, Martins R, Ourselin S, Rossor MN, Fox NC, Cash DM, Weiner MW, Holtzman DM, Buckles VD, Moulder K, Morris JC (2013) Regional variability of imaging biomarkers in autosomal dominant Alzheimer's disease. Proc Natl Acad Sci U S A 110, E4502-E4509.

[15] Quiroz YT, Schultz AP, Chen K, Protas HD, Brickhouse M, Fleisher AS, Langbaum JB, Thiyyagura P, Fagan AM, Shah AR, Muniz M, Arboleda-Velasquez JF, Munoz C, Garcia G, Acosta-Baena N, Giraldo M, Tirado V, Ramírez DL, Tariot PN, Dickerson BC, Sperling RA, Lopera F, Reiman EM (2015) Brain imaging and blood biomarker abnormalities in children with autosomal dominant Alzheimer disease: A cross-sectional study. JAMA Neurol 72, 912-919.

[16] Villain N, Fouquet M, Baron JC, Mézenge F, Landeau B, de La Sayette V, Viader F, Eustache F, Desgranges B, Chételat G (2010) Sequential relationships between grey matter and white matter atrophy and brain metabolic abnormalities in early Alzheimer's disease. Brain 133, 3301-3314.

[17] Roher AE, Maarouf CL, Malek-Ahmadi M, Wilson J, Kokjohn TA, Daugs ID, Whiteside CM, Kalback WM, Macias MP, Jacobson SA, Sabbagh MN, Ghetti B, Beach TG (2013) Subjects harboring presenilin familial Alzheimer's disease mutations exhibit diverse white matter biochemistry alterations. Am J Neurodegener Dis 18, 187-207.

[18] Albert MS, DeKosky ST, Dickson D, Dubois B, Feldman HH, Fox NC, Gamst A, Holtzman DM, Jagust WJ, Petersen RC, Snyder PJ, Carrillo MC, Thies B, Phelps CH (2011) The diagnosis of mild cognitive impairment due to Alzheimer's disease: Recommendations from the National Institute on Aging-Alzheimer's Association workgroups on diagnostic guidelines for Alzheimer's disease. Alzheimers Dement 7, 270-279.

[19] Acosta-Cabronero J, Williams GB, Pengas G, Nestor PJ (2010) Absolute diffusivities define the landscape of white matter degeneration in Alzheimer's disease. Brain 133, 529539.
[20] Nir TM, Jahanshad N, Villalon-Reina JE, Toga AW, Jack CR, Weiner MW, Thompson PM, Alzheimer's Disease Neuroimaging Initiative (ADNI) (2013) Effectiveness of regional DTI measures in distinguishing Alzheimer's disease, MCI, and normal aging. Neuroimage Clin 3, 180195.

[21] Ukmar M, Makuc E, Onor ML, Garbin G, Trevisiol M, Cova MA (2008) Evaluation of white matter damage in patients with Alzheimer's disease and in patients with mild cognitive impairment by using diffusion tensor imaging. Radiol Med 113, 915-922.

[22] Mielke MM, Kozauer NA, Chan KC, George M, Toroney; $\mathrm{J}$, Zerrate $\mathrm{M}$, Bandeen-Roche K, Wang MC, Vanzijl P, Pekar JJ, Mori S, Lyketsos CG, Albert M (2009) Regionally-specific diffusion tensor imaging in mild cognitive impairment and Alzheimer's disease. Neuroimage 46, 47-55.

[23] Acosta-Cabronero J, Alley S, Williams GB, Pengas G, Nestor PJ (2012) Diffusion tensor metrics as biomarkers in Alzheimer's disease. PLoS One 7, e49072.

[24] Molinuevo JL, Ripolles P, Simó M, Lladó A, Olives J, Balasa M, Antonell A, Rodriguez-Fornells A, Rami L (2014) White matter changes in preclinical Alzheimer's disease: A magnetic resonance imaging-diffusion tensor imaging study on cognitively normal older people with positive amyloid $\beta$ protein 42 levels. Neurobiol Aging 35, 2671-2680.

[25] Ashburner J (2007) A fast diffeomorphic image registration algorithm. Neuroimage 38, 95-113.

[26] Jenkinson M, Smith S (2001) A global optimisation method for robust affine registration of brain images. Med Image Anal 5, 143-156.

[27] Cash DM, Ridgway GR, Liang Y, Ryan NS, Kinnunen KM, Yeatman T, Malone IB, Benzinger TL, Jack CR Jr, Thompson PM, Ghetti BF, Saykin AJ, Masters CL, Ringman JM, Salloway SP, Schofield PR, Sperling RA, Cairns NJ, Marcus DS, Xiong C, Bateman RJ, Morris JC, Rossor MN, Ourselin S, Fox NC, Dominantly InheritedAlzheimer Network (DIAN) (2013) The pattern of atrophy in familial Alzheimer disease: Volumetric MRI results from the DIAN study. Neurology 15, 1425-1433.

[28] Ringman JM, O'Neill J, Geschwind D, Medina L, Apostolova LG, Rodriguez Y, Schaffer B, Varpetian A, Tseng B, Ortiz F, Fitten J, Cummings JL, Bartzokis G (2007) Diffusion tensor imaging in preclinical and presymptomatic carriers of familial Alzheimer's disease mutations. Brain 130, 1767-1776.

[29] Parra MA, Saarimäki H, Bastin ME, Londoño AC, Pettit L, Lopera F, Della Sala S, Abrahams S (2015) Memory binding and white matter integrity in familial Alzheimer's disease. Brain 138, 1355-1369.

[30] Li X, Westman E, Ståhlbom AK, Thordardottir S, Almkvist O, Blennow K, Wahlund LO, Graff C (2015) White matter changes in familial Alzheimer's disease. J Intern Med 278, 211-218.

[31] Ryan NS, Biessels GJ, Kim L, Nicholas JM, Barber PA, Walsh P, Gami P, Morris HR, Bastos-Leite AJ, Schott JM, Beck J, Mead S, Chavez-Gutierrez L, de Strooper B, Rossor MN, Revesz T, Lashley T, Fox NC (2015) Genetic determinants of white matter hyperintensities and amyloid angiopathy in familial Alzheimer's disease. Neurobiol Aging 36, 3140-3151. 
[32] Aoki M, Abe K, Oda N, Ikeda M, Tsuda T, Kanai M, Shoji M, St George-Hyslop PH, Itoyama Y (1997) A presenilin1 mutation in a Japanese family with Alzheimer's disease and distinctive abnormalities on cranial MRI. Neurology 48, 1118-1120.

[33] O'Riordan S, McMonagle P, Janssen JC, Fox NC, Farrell M, Collinge J, Rossor MN, Hutchinson M (2002) Presenilin1 mutation (E280G), spastic paraparesis, and cranial MRI white-matter abnormalities. Neurology 59, 1108-1110.
[34] Takao M, Ghetti B, Murrell JR, Unverzagt FW, Giaccone G, Tagliavini F, Bugiani O, Piccardo P, Hulette CM, Crain BJ, Farlow MR, Heyman A (2001) Ectopic white matter neurons, a developmental abnormality that may be caused by the PSEN1 S169L mutation in a case of familial AD with myoclonus and seizures. J Neuropathol Exp Neurol 60, $1137-1152$. 